\title{
The bacterial profile and antibiotic susceptibility pattern among patients with suspected bloodstream infections, Gondar, north-west Ethiopia
}

This article was published in the following Dove Press journal: Pathology and Laboratory Medicine International

\author{
Abtie Abebaw ${ }^{1}$ \\ Hiwot Tesera ${ }^{2}$ \\ Teshome Belachew ${ }^{3}$ \\ Gebreselassie Demeke \\ Mihiretie' \\ 'Department of Medical Laboratory \\ Science, College of Medicine and \\ Health Science, Debre Markos \\ University, Debre Markos, Ethiopia; \\ ${ }^{2}$ Department of Medical Laboratory \\ Science, University of Gondar College \\ of Medicine and Health Science, \\ Gondar, Ethiopia; ${ }^{3}$ Department of \\ Medical Laboratory Science, Bahirdar \\ University College of Medicine and \\ Health Science, Bahir Dar, Ethiopia
}

Background: The bacteria most likely to cause bacteremia include Staphylococcus, Streptococcus, Enterococcus, Escherichia, Klebsiella, Pseudomonas, Enterobacter, Haemophilus, and Neisseria genera. Bloodstream infections remain one of the most important causes of morbidity and mortality throughout the world. Drug-resistant pathogens are becoming the most challenging problem and they have different economic and social impacts around the world.

Objective: To study the bacterial profile and antibiotic susceptibility among bacteremiasuspected patients in the University of Gondar Teaching Hospital from September 2003 to February 2013.

Materials and method: This retrospective cross-sectional study was conducted from March to May 2013 at the University of Gondar. Data were collected and extracted manually from the microbiology registration books of the hospital laboratory using checklists and were checked for its completeness and consistency.

Result: Among a total of 856 blood samples analyzed, 169 (19.7\%) cases were bacteremia confirmed. From the confirmed cases, 98 (58\%) were male and $71(42 \%)$ female. Culture positivity rate was highest (44\%) in the age group of $\leq 28$ days followed by the age group of 29 days -5 years. Conclusion: In our study, coagulase-negative staphylococci were the most common causative agent for bacteremia among the Gram-positive isolates. The overall antimicrobial susceptibility pattern of the Gram-positive isolates was an intermediate level of resistance $(60 \%-80 \%)$, but Gram-negative bacteria showed a high level of resistance ( $>80 \%)$ against ampicillin and amoxicillin. Keywords: bacteremia, drug susceptibility, sepsis, resistant

\section{Introduction}

Bacteremia is the presence of bacteria in the bloodstream and occurs when bacteria enter the bloodstream. Blood by its nature is sterile. So the presence of any bacteria in circulating blood is a threat to every organ in the body. ${ }^{1}$ Most episodes of occult bacteremia spontaneously resolve and serious sequelae are increasingly uncommon. However, sometimes bacteremia can have adverse consequences including multiple organ failures, septic shock, disseminated intravascular coagulation, and death. Generally, the factors that contribute to the initiation of bloodstream infection are immune suppressive agents, widespread use of broad-spectrum antibiotics that suppress the normal flora and allow the emergence of resistant strains, invasive procedures and prolonged survival-debilitated and seriously ill patients. ${ }^{1-3}$
Correspondence: Gebreselassie Demeke Mihiretie

Department of Medical Laboratory Science, College of Medicine and Health Science, Debre Markos University, PO Box 269, Debre Markos, Ethiopia Tel +25I 924338828

Email gebredemeke@yahoo.com 
Bacteremia is related to the presence of viable bacteria in the blood confirmed by cultures in which contamination has been effectively ruled out. ${ }^{4,5}$ This may or may not have any clinical significance because harmless, transient bacteremia may occur following dental work or other minor medical procedures; however, it is generally clinically benign and self-resolving in people who do not have an underlying illness or immune deficiency or a turbulent cardiac blood flow.

Several types of bacteria live in different parts of the human body as normal flora. But when bacterial niches are disturbed by different factors and the immunity of individuals are compromised by different factors they may enter into the blood from the skin or urinary tract causing fatal disease. ${ }^{6}$ Bacteremia may also be related to a failure of the immune system that is not able to control bacterial dissemination from the surgical wound, gastrointestinal tract, or urinary tract. ${ }^{1,3,6,7}$

The most common bacteria that cause bacteremia include members of Staphylococcus, Streptococcus, Enterococcus, Escherichia, Klebsiella, Pseudomonas, Enterobacter, Haemophilus, and Neisseria genera. ${ }^{1,8,9}$ Timely and appropriate use of antibiotics is the appropriate way to treat bacteremia. ${ }^{10}$ Despite such precautions, the development of antibioticresistant strains of bacteria (eg, methicillin-resistant Staphylococcus aureus or MRSA) has led to an increase in the incidence of severe bacteremia since the late 1960s. ${ }^{11}$

\section{Materials and methods}

A retrospective cross-sectional study was conducted in the University of Gondar Teaching Hospital from March to May 2013. The University of Gondar Teaching Hospital is a tertiary level hospital providing both inpatient and outpatient services to more than 5 million people in the region. All bacteremia-suspected patients who have symptoms of fever or chills, including shaking, confusion, and a rapid and shallow rate of breathing, are eligible for a blood culture diagnosis of bacteremia.

\section{Bacteriological investigation Culture media}

Laboratory investigation standard operation procedures based on the Clinical and Laboratory Standards Institute's (CLSI) recommendations were used by the University of Gondar Teaching Hospital laboratory to isolate bacteria from a blood sample. A 5-mL blood sample was collected aseptically and added to $45 \mathrm{~mL}$ of Trypanosoma broth (1:9 ratio) and incubated at $37^{\circ} \mathrm{C}$. The turbidity (sign of bacterial growth) was checked daily until the 14th day to report no bacterial growth. Turbid broth cultures were subcultured into MacConkey agar, Blood agar plates and Chocolate agar plates (Oxoid ${ }^{\mathrm{TM}}$ Ltd, Thermo Fisher Scientific, Waltham, MA, USA) and incubated at $37^{\circ} \mathrm{C}$ for $24-48$ hours. The Chocolate agar-incubated cultures were carried out in a microaerophilic atmosphere by using a candle jar. Identification of bacteria was made using colony characteristics, Gram reaction of the organisms, and biochemical tests following standard procedures. ${ }^{12}$

\section{Antimicrobial susceptibility testing}

Antimicrobial susceptibility testing was performed for all blood culture isolates according to the criteria of the CLSI by the disk diffusion method with the exception of $S$. aureus where the susceptibility test for vancomycin was done by dilution method. ${ }^{12,13}$ From a pure culture, three to five selected colonies of bacteria were taken and transferred to a tube containing $5-\mathrm{mL}$ sterile normal saline and mixed gently to a homogenous suspension and incubated at $37^{\circ} \mathrm{C}$ until the turbidity of the suspension become adjusted to a McFarland 0.5 . A sterile cotton swab was used, and the excess suspension was removed by gentle rotation of the swab against the surface of the tube. The swab was then used to distribute the bacteria evenly over the entire surface of Mueller Hinton agar. The inoculated plates were left at room temperature to dry for 3-5 minutes, and a set of antibiotic discs were then placed on the surface of a Muller-Hinton plate. The drugs for disc diffusion testing were in the following concentrations: Ampicillin $(10 \mu \mathrm{g})$, Amoxicillin $(25 \mu \mathrm{g})$, Gentamicin $(10 \mu \mathrm{g})$, Erythromycin $(15 \mu \mathrm{g})$, Pencillin $(10 \mu \mathrm{g})$, Nalidixin acid $(30 \mu \mathrm{g})$, Ciprofloxacin $(5 \mu \mathrm{g})$, Chlorapinicole $(30 \mu \mathrm{g})$, Co-Trimoxazol $(25 \mu \mathrm{g})$, Tetracyline $(30 \mu \mathrm{g})$, Chloramphenicol $(30 \mu \mathrm{g})$, Norfloxacin $(10 \mu \mathrm{g})$, Augmentin $(30 \mu \mathrm{g})$, Ceftriaxone $(30 \mu \mathrm{g})$, Cefotaxime $(30 \mu \mathrm{g})$, and Vancomycin (30 $\mu \mathrm{g})$. All antimicrobial disc used for the study were obtained from Oxoid ${ }^{\mathrm{TM}}$ Ltd (Thermo Fisher Scientific). Diameters of a zone of inhibition around the disk were measured with the ruler and the isolates were classified as sensitive, intermediate, and resistant according to the standardized table supplied by the CLSI. Bacteria resisting more than two drugs of the different families are considered as "multi-drug resistant". ${ }^{13}$ High, intermediate and low levels of resistance are defined when the percentage of resistance is $>80 \%, 60 \%-80 \%$, and $<60 \%$ respectively.

\section{Quality control}

The quality of blood culture was maintained by proper antiseptic techniques during collection of the blood samples, with an appropriate sample volume taken, an appropriate time of collection and a patient history taken including 
current medications. Culture media were tested for sterility by incubating overnight at $37^{\circ} \mathrm{C}$ and for performance by inoculating known standard strains. Standard strains of Escherichia coli American Type Culture Collection (ATCC) 25922 and S. aureus ATCC 25923 were used during culture and antimicrobial susceptibility testing. ${ }^{13}$

\section{Data collection and analysis}

Raw data were extracted manually from the microbiology registration books of the hospital laboratory by investigators and were analyzed and expressed descriptively.

\section{Ethical considerations}

An ethical approval letter was obtained from the School of Biomedical and Laboratory Science, College of Medicine and Health Sciences, University of Gondar. Official permission was obtained from the School of Biomedical and Laboratory Science and Hospital Diagnostic Center prior to the commencement of data collection. The data were retrospective and, therefore, there was no need for consent. The Gondar University ethical committee approved permission to collect the data. Patient data were kept confidentially using codes.

\section{Results}

\section{Sociodemographic characteristics}

During the period 2003-2013, a total of 856 blood samples were analyzed and bacteremia was confirmed in 169 (19.7\%) cases. From the confirmed cases, 98 (58\%) were male and $71(42 \%)$ female. Culture positivity rate was highest in the age group of $\leq 28$ days $(44 \% ; 55 / 125)$ followed by those in the age group of 29 days- 5 years (Table 1 ).

Table I Prevalence of bacteremia among sex and age groups of suspected patients in the University of Gondar Teaching Hospital from September 2003 to February 2013

\begin{tabular}{llll}
\hline \multicolumn{2}{l}{ Characteristics } & $\begin{array}{l}\text { No. } \\
\text { tested }\end{array}$ & $\begin{array}{l}\text { Positive } \\
\text { results, } \mathbf{n}(\%)\end{array}$ \\
\hline Gender & Male & 428 & $98(23)$ \\
& Female & 428 & $71(17)$ \\
Age & $\leq 28$ days & 125 & $55(44)$ \\
& 29 days -5 years & 90 & $30(33.3)$ \\
& $6-14$ years & 139 & $19(13.7)$ \\
& $15-23$ years & 160 & $20(12.5)$ \\
& $24-32$ years & 180 & $19(10.6)$ \\
& $33-41$ years & 87 & $12(13.8)$ \\
& $42-50$ years & 46 & $9(19.6)$ \\
& $51-59$ years & 6 & $0(0.0)$ \\
Total & $\geq 60$ years & 23 & $5(21.7)$ \\
\hline
\end{tabular}

\section{Bacterial isolate}

From a total of 856 bacteremia-suspected cases, 169 were positive. Mixed bacterial growths were observed in five specimens so that a total of 174 bacteria were isolated (Table 2). From the isolated bacteria, Gram-positive bacteria were more prevalent than Gram-negative bacteria. The most commonly isolated bacteria were coagulase-negative staphylococci (CoNS) followed by S. aureus, E. coli, and Citrobacter species.

\section{Antibiotic susceptibility pattern Antibiotic susceptibility pattern of Gram-positive bacteria}

The observed drug susceptibility pattern of Gram-positive isolates indicated an intermediate level of resistance $(60 \%-$ $80 \%$ ). In response to the penicillin, the resistance pattern was $72 \%$, in ampicillin, it was $63.4 \%$, in erythromycin, it was $60.3 \%$ with only a low level of resistance $(60 \%)$ in the rest of the tested drugs (Table 3 ).

\section{Antibiotic susceptibility pattern of Gram-negative bacteria}

The antibiotic susceptibility test for Gram-negative bacteria revealed a high level of resistance ( $>80 \%$ ) for ampicillin (90.4\%), and for amoxicillin (88.7\%), an intermediate level of resistance to tetracycline $(74.2 \%)$ and cotrimoxazole $(62.3 \%)$, and a low level of resistance to the remaining drugs (Table 4).

Table 2 The frequency of bacterial isolates from patients with bacteremia at the University of Gondar Teaching Hospital from September 2003 to February 2013

\begin{tabular}{lll}
\hline Sr. no & Organism & Frequency (\%) \\
\hline 1 & CoNS & $55(31.6)$ \\
2 & Staphylococcus aureus & $48(27.6)$ \\
3 & Escherichia coli & $15(8.6)$ \\
4 & Citrobacter spp. & $8(4.6)$ \\
5 & Salmonella enterica subsp. arizonae & $6(3.4)$ \\
6 & Pseudomonas aeruginosa & $6(3.4)$ \\
7 & Streptococcus pyogenes & $6(3.4)$ \\
8 & Klebsiella pneumoniae & $6(3.4)$ \\
9 & Enterobacter spp. & $6(3.4)$ \\
10 & Klebsiella pneumoniae subsp. ozaenae & $4(2.3)$ \\
11 & Salmonella spp. & $4(2.3)$ \\
12 & Providentia spp. & $3(1.7)$ \\
13 & Proteus spp. & $3(1.7)$ \\
14 & Streptococcus viridans & $2(1.1)$ \\
15 & Klebsiella pneumoniae subsp. rhinoscleromatis & $1(0.6)$ \\
16 & Enterococcus spp. & $1(0.6)$ \\
& Total & $174(100)$ \\
\hline
\end{tabular}

Abbreviation: CoNS, coagulase-negative staphylococci. 
Table 3 Antibiotic susceptibility pattern of Gram-positive bacteria isolated from blood culture at the University of Gondar Teaching Hospital from September 2003 to February 2013

\begin{tabular}{|c|c|c|c|c|c|c|c|c|c|c|c|}
\hline Isolates & & $\begin{array}{l}\text { Amp } \\
\text { n/total } \\
(\%)\end{array}$ & $\begin{array}{l}\text { Amx } \\
\text { n/total } \\
(\%)\end{array}$ & $\begin{array}{l}\text { Cro } \\
\text { n/total } \\
(\%)\end{array}$ & $\begin{array}{l}\text { Ery } \\
\text { n/total } \\
(\%)\end{array}$ & $\begin{array}{l}\text { Cn } \\
\text { n/total } \\
(\%)\end{array}$ & $\begin{array}{l}\text { Nor } \\
\text { n/total } \\
(\%)\end{array}$ & $\begin{array}{l}\text { Vanco } \\
\text { n/total } \\
(\%)\end{array}$ & $\begin{array}{l}\mathrm{Pg} \\
\mathrm{n} / \text { total } \\
(\%)\end{array}$ & $\begin{array}{l}\text { Cip } \\
\text { n/total } \\
(\%) \\
\end{array}$ & $\begin{array}{l}\text { Caf } \\
\text { n/total } \\
(\%) \\
\end{array}$ \\
\hline \multirow[t]{3}{*}{ CoNS (55) } & $S$ & $18(32.7)$ & $26(47.3)$ & $37(67.3)$ & $25(45.5)$ & $26(47.3)$ & $36(65.5)$ & $52(94.5)$ & $13(23.5)$ & $34(62)$ & $27(49)$ \\
\hline & I & $2(3.6)$ & $3(5.4)$ & 0 & $2(3.5)$ & 0 & 0 & 0 & $3(5.5)$ & $2(3.5)$ & 0 \\
\hline & $\mathrm{R}$ & $35(63.7)$ & $26(47.3)$ & $18(32.7)$ & $28(5 I)$ & $29(52.7)$ & $19(34.5)$ & $3(5.5)$ & $39(7 I)$ & $19(34.5)$ & $28(5 \mathrm{I})$ \\
\hline Staphylococcus & $\mathrm{S}$ & $10(20.8)$ & $10(20.8)$ & $23(48)$ & $13(27)$ & $27(56.2)$ & $19(39.5)$ & $39(81.2)$ & $8(16.7)$ & $31(64.6)$ & $29(60.4)$ \\
\hline \multirow[t]{2}{*}{ aureus (48) } & I & $4(8.4)$ & $3(6.2)$ & 0 & I (2.2) & $3(6.2)$ & $2(4.2)$ & 0 & $2(4.2)$ & $3(6.2)$ & 0 \\
\hline & $\mathrm{R}$ & $34(70.8)$ & $35(73)$ & $25(52)$ & $34(70.8)$ & $18(37.5)$ & $27(56.3)$ & $9(18.8)$ & $38(79.1)$ & $14(29.2)$ & $19(39.6)$ \\
\hline Streptococcus & $S$ & $6(100)$ & $6(100)$ & $5(83.3)$ & $3(50)$ & $2(33.3)$ & $3(50)$ & $6(100)$ & $5(83.3)$ & $3(50)$ & $4(66.7)$ \\
\hline \multirow[t]{2}{*}{ pyogenes (6) } & I & 0 & 0 & 0 & 0 & $4(66.7)$ & 0 & 0 & 0 & 0 & 0 \\
\hline & $\mathrm{R}$ & 0 & 0 & I (16.7) & $3(50)$ & 0 & $3(50)$ & 0 & I (I6.7) & $3(50)$ & $2(33.3)$ \\
\hline Streptococcus & $\mathrm{S}$ & I (50) & 0 & - & 0 & 0 & 0 & I (50) & 0 & $2(100)$ & I (50) \\
\hline \multirow{2}{*}{ viridans (2) } & I & 0 & 0 & - & 0 & 0 & 0 & 0 & 0 & 0 & I (50) \\
\hline & $\mathrm{R}$ & I (50) & $2(100)$ & - & $2(100)$ & $2(100)$ & $2(100)$ & I (50) & $2(100)$ & 0 & 0 \\
\hline Enterococcus spp. & $\mathrm{S}$ & 0 & 0 & - & - & $I(100)$ & $I(100)$ & - & - & - & \\
\hline \multirow[t]{2}{*}{ (I) } & I & 0 & 0 & - & - & 0 & 0 & - & - & - & \\
\hline & $\mathrm{R}$ & $I(100)$ & $I(100)$ & - & - & 0 & 0 & - & - & - & \\
\hline \multirow[t]{4}{*}{ Total } & $\mathrm{S}$ & 35 (3I. 2) & $42(37.5)$ & $65(59.6)$ & $41(37)$ & $56(50)$ & $59(52.7)$ & $98(88.3)$ & $26(23.5)$ & $70(63)$ & $61(55)$ \\
\hline & I & $6(5.4)$ & $6(5.4)$ & 0 & $3(2.7)$ & $7(6.3)$ & $2(1.8)$ & 0 & $5(4.5)$ & $5(4.5)$ & I (0.9) \\
\hline & $\mathrm{R}$ & 71 (63.4) & $64(57.1)$ & $44(40.4)$ & $67(60.3)$ & 49 (43.7) & $5 I(45.5)$ & $13(11.7)$ & $80(72)$ & $36(32.5)$ & $49(44.1)$ \\
\hline & $\mathrm{T}$ & 112 & 112 & 109 & 111 & 112 & 112 & 111 & 111 & 111 & 111 \\
\hline
\end{tabular}

Note: $(\%=n /$ total $), n=$ number of sensitive isolates.

Abbreviations: Amp, ampicillin; Amx, amoxicillin; Cro, ceftriaxone; Ery, erythromycin; Cn, gentamicin; Nor, norfloxacin; Vanco, vancomycin, Pg, penicillin G; Cip, ciprofloxacin; Caf, chloramphenicol; CoNS, coagulase-negative staphylococci; S, sensitive; I, intermediate; R, resistant; T, total.

\section{Multidrug resistance pattern of bacterial isolates}

Multidrug resistance strains were common for both Gramnegative and Gram-positive isolates. Out of 174 isolates, 165 (94.8\%) were found to be resistant to at least one antibiotic used in the susceptibility tests and $9(5.2 \%)$ isolates were found to not be resistant to antibiotics used for the susceptibility tests. Resistance to two or more drugs was observed in 94 (84\%) of Gram-positive and 57 (92\%) of Gram-negative isolates (Table 5).

\section{Discussion}

The prevalence rate of bacteremia in Gondar University Teaching Hospital is comparable to reports in Tikur Anbessa Hospital, Addis Ababa, Ethiopia $\left(21.4 \%,{ }^{14,15}\right.$ and in India $(20.5 \%) .{ }^{15}$ However, our finding is slightly higher than the research done in Kasturba Hospital, India $(17.8 \%)^{16}$ and Uganda (17.1\%), ${ }^{17}$ but lower than research done in Gondar University Hospital (24.2\%). ${ }^{18}$ The research was done in Teheran Hospital, Iran, Imam Khomeini Teaching Hospital, Iran and in Jimma and shows that the prevalence of bacteremia was $10.23 \%, 5.6 \%$, and $8.8 \%$ respectively, ${ }^{10,19,20}$ which are all lower values than in our study. The difference could be due to a variation in the blood culture system, the study design, the geographical location, and/or epidemiological differences in the etiological agents.

Our study shows that males are more likely to suffer from bacteremia than females. This is similar to the study conducted in Iran. ${ }^{24}$ The highest isolation rate was observed in the age group of $\leq 28$ days followed by the age group of 29 days -5 years and the age group of 60 years and above. This is comparable with the previous study conducted at the University of Gondar Teaching Hospital. ${ }^{21}$ This could be explained by the fact that extreme ages are susceptible to infection because of lower immunity. And also the age group of $\leq 5$ years are exposed to microorganisms because they are fed contaminated food, soil, and other materials due to lack of knowledge about infectious diseases and their transmission, and lack of personal hygiene.

The observation in this study showed that Gram-positive bacteria were predominant compared with Gram-negative bacteria which is in line with other studies conducted in Ethiopia $^{10,18}$ and elsewhere in the world. ${ }^{22}$ The most isolated organism in our study was CoNS followed by $S$. aureus. This finding is in line with previous studies conducted in Ethiopia ${ }^{10,18}$ and other countries. ${ }^{23}$ But this finding is contradictory to other reports, such as a study conducted in Kasturba Hospital, India, 
Table 4 Antibiotic susceptibility pattern of Gram-negative bacteria isolated from blood culture at the University of Gondar Teaching Hospital from September 2003 to February 2013

\begin{tabular}{|c|c|c|c|c|c|c|c|c|c|c|c|}
\hline Isolates & & Amp & Amx & Cro & Cip & Cn & $\mathbf{N a}$ & Nor & Sxt & Te & Cxt \\
\hline \multirow{3}{*}{ Escherichia coli (15) } & $\mathrm{S}$ & I (6.6) & $2(13.3)$ & II (73.3) & $10(66.7)$ & $7(46.7)$ & $9(60)$ & $10(66.7)$ & $4(26.7)$ & $3(20)$ & $8(53.3)$ \\
\hline & 1 & 0 & 0 & $2(13.3)$ & 0 & 0 & 0 & 0 & 0 & $2(13.3)$ & 0 \\
\hline & $\mathrm{R}$ & $14(92.3)$ & $13(86.7)$ & $2(12.3)$ & $5(33.3)$ & $8(53.3)$ & $6(40)$ & $5(33.3)$ & II (73.3) & $10(66.7)$ & $7(46.7)$ \\
\hline \multirow[t]{3}{*}{ Citrobacter spp. (8) } & $S$ & 0 & 0 & $5(62.5)$ & $5(62.5)$ & $2(25)$ & $5(62.5)$ & $7(87.5)$ & $7(87.5)$ & I (I2.5) & $5(62.5)$ \\
\hline & I & 0 & 0 & 0 & 0 & 0 & $2(25)$ & 0 & 0 & 0 & 0 \\
\hline & $\mathrm{R}$ & $8(100)$ & $8(100)$ & $3(37.5)$ & $3(37.5)$ & $6(75)$ & $\mathrm{I}(12.5)$ & I (I2.5) & I (I2.5) & $7(87.5)$ & $3(37.5)$ \\
\hline Pseudomonas & $S$ & 0 & 0 & $4(66.7)$ & $3(50)$ & $3(50)$ & - & $5(83.3)$ & $2(33.3)$ & $2(33.3)$ & $4(66.7)$ \\
\hline \multirow[t]{2}{*}{ aeruginosa (6) } & I & 0 & 0 & $2(33.3)$ & 0 & 0 & - & 0 & 0 & 0 & $2(33.3)$ \\
\hline & $\mathrm{R}$ & $6(100)$ & $6(100)$ & 0 & $3(50)$ & $3(50)$ & - & I (I6.7) & $4(66.7)$ & $4(66.7)$ & 0 \\
\hline Salmonella enterica & $S$ & 0 & 0 & 0 & $5(83.3)$ & 0 & $3(50)$ & $5(83.3)$ & $2(33.3)$ & I (I6.7) & $5(83.3)$ \\
\hline \multirow{2}{*}{ subsp. Arizonae (6) } & I & 0 & 0 & 0 & 0 & 0 & $3(50)$ & 0 & 0 & 0 & 0 \\
\hline & $\mathrm{R}$ & $6(100)$ & $6(100)$ & $6(100)$ & I (I6.7) & $6(100)$ & 0 & I (I6.7) & $4(66.7)$ & $5(83.3)$ & I (16.7) \\
\hline Klebsiella pneumoniae & $\mathrm{S}$ & 0 & 0 & $2(33.3)$ & $2(33.3)$ & $2(33.3)$ & - & $6(100)$ & $2(33.3)$ & $2(33.3)$ & - \\
\hline \multirow[t]{2}{*}{ (6) } & I & 0 & 0 & 0 & 0 & I (16.7) & - & 0 & 0 & 0 & - \\
\hline & $\mathrm{R}$ & $6(100)$ & $6(100)$ & $4(66.7)$ & $4(66.7)$ & $3(50)$ & - & 0 & $4(66.7)$ & $4(66.7)$ & - \\
\hline \multirow[t]{3}{*}{ Enterobacter spp. (6) } & $S$ & I (I6.7) & I (I6.7) & 0 & $6(100)$ & I (I6.7) & $3(50)$ & $5(83.3)$ & 0 & $2(33.3)$ & $2(33.3)$ \\
\hline & I & 0 & 0 & $3(50)$ & 0 & 0 & 0 & 0 & 0 & 0 & 0 \\
\hline & $\mathrm{R}$ & $5(83.3)$ & $5(83.3)$ & $3(50)$ & 0 & $5(83.3)$ & $3(50)$ & I (I6.7) & $6(100)$ & $4(66.7)$ & $4(66.7)$ \\
\hline \multirow[t]{3}{*}{ Salmonella spp. (4) } & $S$ & 0 & 0 & $4(100)$ & $2(50)$ & $4(100)$ & $3(75)$ & - & I (25) & 0 & $4(100)$ \\
\hline & I & 0 & 0 & 0 & 0 & 0 & 0 & - & 0 & 0 & 0 \\
\hline & $\mathrm{R}$ & $4(100)$ & $4(100)$ & 0 & $2(50)$ & 0 & I (25) & - & $3(75)$ & $4(100)$ & 0 \\
\hline Klebsiella pneumoniae & $\mathrm{S}$ & 0 & 0 & $4(100)$ & $4(100)$ & $2(50)$ & $4(100)$ & $3(75)$ & I (25) & 0 & I \\
\hline \multirow{2}{*}{ subsp. Ozaenae (4) } & I & $3(75)$ & $3(75)$ & 0 & 0 & 0 & 0 & 0 & 0 & 0 & 0 \\
\hline & $\mathrm{R}$ & $\mathrm{I}(25)$ & $\mathrm{I}(25)$ & 0 & 0 & $2(50)$ & 0 & I (25) & $3(75)$ & $4(100)$ & $3(75)$ \\
\hline \multirow[t]{3}{*}{ Providential spp. (3) } & $S$ & 0 & 0 & $3(100)$ & $3(100)$ & - & $3(100)$ & $3(100)$ & $2(66.7)$ & I (33.3) & - \\
\hline & I & 0 & 0 & 0 & 0 & - & 0 & 0 & 0 & 0 & - \\
\hline & $\mathrm{R}$ & $3(100)$ & $3(100)$ & 0 & 0 & - & 0 & 0 & I (33.3) & $2(66.7)$ & - \\
\hline \multirow[t]{3}{*}{ Proteus spp. (3) } & $S$ & I (33.3) & I (33.3) & $2(66.7)$ & - & $3(100)$ & $2(66.7)$ & $3(100)$ & $2(66.7)$ & I (33.3) & $2(66.7)$ \\
\hline & I & 0 & 0 & 0 & - & 0 & 0 & 0 & 0 & 0 & I (33.3) \\
\hline & $\mathrm{R}$ & $2(66.7)$ & $2(66.7)$ & I (33.3) & - & 0 & I (33.3) & 0 & I (33.3) & $2(66.7)$ & 0 \\
\hline Klebsiella pneumoniae & $\mathrm{S}$ & 0 & 0 & - & - & - & $I(100)$ & $I(100)$ & - & $I(100)$ & $I(100)$ \\
\hline subsp. rhinoscleromatis & 1 & 0 & 0 & - & - & - & 0 & 0 & - & 0 & 0 \\
\hline (I) & $\mathrm{R}$ & $I(100)$ & $I(100)$ & - & - & - & 0 & 0 & - & 0 & 0 \\
\hline \multirow[t]{4}{*}{ Total } & $S$ & $3(4.8)$ & $4(6.5)$ & $35(57.4)$ & $40(69)$ & $24(4 \mid .4)$ & $33(66)$ & 48 (82.7) & $23(37.7)$ & $14(22.5)$ & $32(60.4)$ \\
\hline & 1 & $3(4.8)$ & $3(4.8)$ & 7 (II.5) & 0 & I (I.7) & $5(10)$ & 0 & 0 & $2(3.3)$ & $3(5.6)$ \\
\hline & $\mathrm{R}$ & $56(90.4)$ & 55 (88.7) & $19(31.1)$ & $18(3 \mid)$ & $33(56.9)$ & $12(24)$ & $10(17.2)$ & $38(62.3)$ & $46(74.2)$ & $18(34)$ \\
\hline & $T$ & 62 & 62 & 61 & 58 & 58 & 50 & 58 & 61 & 62 & 53 \\
\hline
\end{tabular}

Abbreviations: Amp, ampicillin; Amx, amoxicillin; Cro, ceftriaxone; Cip, ciprofloxacin; Cn, gentamicin; Na, nalidixic acid; Nor, norfloxacin; Sxt, trimethoprimsulfamethoxazole; Te, tetracycline; Cxt, cefoxitin; S, sensitive; I, intermediate; R, resistant; T, total.

Banaras Hindu University Hospital, India, Teheran Hospital, Iran, Imam Khomeini Teaching Hospital, Iran and Uganda, showing that Gram-negative bacteria were the most causative agents of bacteremia. ${ }^{16,17,19,20,22}$ This might be due to the organisms responsible for bacteremia varying across geographical boundaries. Though, generally, the kind of bacteria isolated from blood in our study is similar to previous findings from Ethiopia $^{10,18}$ and elsewhere in the world. . $^{1723,24}$

In our study, CoNS is the most common causative agent for bacteremia among Gram-positive isolates, which is similar to the studies conducted in Jimma, Addis Ababa, and Gondar. ${ }^{10,18}$ This may be due to the fact that most CoNS are the normal flora of the skin. So, during blood collection, they may contaminate the blood. And also it may be the expanding use of intravascular catheters and indwelling prosthetic devices causing the increase of nosocomial bacteremia caused by CoNS because they infect a wide variety of prosthetic medical devices. Among Gram-negative bacteria, $E$. coli was the predominant species which is comparable to the previous study conducted in Jimma. ${ }^{10}$ This may be due to its association with high-risk surgical procedures, particularly in the digestive or urinary tract that releases bacteria from sequestered sites into the blood, which may carry infection to remote parts of the body. 
Table 5 Multi-drug resistance pattern of bacterial isolates from blood culture at the University of Gondar Teaching Hospital from September 2003 to February 2013

\begin{tabular}{|c|c|c|c|c|c|c|c|c|c|}
\hline Isolates & Frequency & R0 (\%) & RI (\%) & $\mathbf{R 2}(\%)$ & R3 (\%) & R4 (\%) & R5 (\%) & R6 (\%) & $>$ R7 (\%) \\
\hline Gram positive & 112 & $7(6.2)$ & II (9.8) & $23(20.5)$ & $13(11.6)$ & $8(7.1)$ & $12(10.8)$ & $13(11.6)$ & $25(22.3)$ \\
\hline CoNS & 55 & $4(7.3)$ & $7(12.7)$ & II (20) & II (20) & $2(3.6)$ & $7(12.7)$ & $3(5.4)$ & $10(18.2)$ \\
\hline Staphylococcus aureus & 48 & I (2.I) & $4(8.3)$ & $9(18.7)$ & $I(2.1)$ & $6(12.5)$ & $4(8.3)$ & $9(18.7)$ & $14(29.2)$ \\
\hline Streptococcus pyogen & 6 & $2(33.3)$ & $0(0.00)$ & $3(50)$ & $0(0.00)$ & $0(0.00)$ & $0(0.00)$ & $0(0.00)$ & I (16.7) \\
\hline Streptococcus viridans & 2 & $0(0.00)$ & $0(0.00)$ & $0(0.00)$ & $0(0.00)$ & $0(0.00)$ & I (50) & I (50) & $0(0.00)$ \\
\hline Enterococcus spp. & I & $0(0.00)$ & $0(0.00)$ & $0(0.00)$ & $I(100)$ & $0(0.00)$ & $0(0.00)$ & $0(0.00)$ & $0(0.00)$ \\
\hline Gram negative & 62 & $2(3.2)$ & $3(4.8)$ & $10(16.1)$ & $15(24.2)$ & II (17.7) & $13(20.9)$ & $6(9.7)$ & $2(3.2)$ \\
\hline Escherichia coli & 15 & I (6.7) & $0(0.00)$ & $4(26.7)$ & $2(13.3)$ & $2(13.3)$ & I (6.7) & $3(20)$ & $2(13.3)$ \\
\hline Citrobacter spp. & 8 & $0(0.00)$ & I (I2.5) & I (I2.5) & I (12.5) & $3(37.5)$ & I $(12.5)$ & I (12.5) & $0(0.00)$ \\
\hline Salmonella enterica subsp. arizonae & 6 & $0(0.00)$ & $0(0.00)$ & $0(0.00)$ & I (I6.7) & $\mathrm{I}(16.7)$ & $3(50)$ & I (16.7) & $0(0.00)$ \\
\hline Pseudomonas aeruginosa & 6 & $0(0.00)$ & $0(0.00)$ & $2(33.3)$ & $2(33.3)$ & I (I6.7) & I (I6.7) & $0(0.00)$ & $0(0.00)$ \\
\hline Klebsiella pneumonia & 6 & $0(0.00)$ & I (16.7) & $0(0.00)$ & I (I6.7) & $\mathrm{I}(16.7)$ & $2(33.3)$ & I (16.7) & $0(0.00)$ \\
\hline Enterobacter spp. & 6 & $0(0.00)$ & $0(0.00)$ & I (I6.7) & I (I6.7) & $0(0.00)$ & $4(66.7)$ & $0(0.00)$ & $0(0.00)$ \\
\hline Salmonella spp. & 4 & $0(0.00)$ & I (25) & $0(0.00)$ & $\mathrm{I}(25)$ & $\mathrm{I}(25)$ & $I(25)$ & $0(0.00)$ & $0(0.00)$ \\
\hline Klebsiella pneumoniae subsp. ozaenae & 4 & I (25) & $0(0.00)$ & I (25) & I (25) & I (25) & $0(0.00)$ & $0(0.00)$ & $0(0.00)$ \\
\hline Providential spp. & 3 & $0(0.00)$ & $0(0.00)$ & $0(0.00)$ & $3(100)$ & $0(0.00)$ & $0(0.00)$ & $0(0.00)$ & $0(0.00)$ \\
\hline Proteus spp. & 3 & $0(0.00)$ & $0(0.00)$ & I (33.3) & I (33.3) & I (33.3) & $0(0.00)$ & $0(0.00)$ & $0(0.00)$ \\
\hline $\begin{array}{l}\text { Klebsiella pneumoniae subsp. } \\
\text { rhinoscleromatis }\end{array}$ & 1 & $0(0.00)$ & $0(0.00)$ & $0(0.00)$ & $I(100)$ & $0(0.00)$ & $0(0.00)$ & $0(0.00)$ & $0(0.00)$ \\
\hline
\end{tabular}

Abbreviation: CoNS, coagulase-negative staphylococci.

This study also provides insight into the drugs susceptibility profile of bacteria isolated from blood. The overall antimicrobial susceptibility pattern of Gram-positive bacteria in our study shows an intermediate level of resistance $(60 \%-80 \%)$ was observed in response to penicillin, ampicillin, and erythromycin, whereas antibiotics like vancomycin, ciprofloxacin, and ceftriaxone show a high sensitivity pattern relative to other tested drugs (Table 4), which is slightly different from the study conducted in Jimma ${ }^{10}$ and elsewhere in the world. ${ }^{16,17,23,24}$

The overall antimicrobial susceptibility pattern of Gram-negative bacteria shows that they have a high level of resistance ( $>80 \%)$ against ampicillin and amoxicillin and an intermediate level of resistance to tetracycline and co-trimoxazole. However, high sensitivity was observed to norfloxacin and ciprofloxacin relative to other tested drugs, which is in agreement with the previous studies conducted in Jimma ${ }^{16}$ and elsewhere in the world. ${ }^{16,20}$ In our study, ciprofloxacin, vancomycin, ceftriaxone, and norfloxacin were the most effective drug when compared to other drugs tested against both Gram-negative and Gram-positive isolates. This finding is comparable to the studies conducted in Ethiopia ${ }^{10,18}$ and elsewhere in the world. ${ }^{17,20}$ The effectiveness of these drugs against the tested organisms in our study may be a reflection of the infrequency of prescription of these drugs by physicians and the drugs may be higher cost relative to others, so people do not take these drugs for self-medication.

In this study, multiple drug resistance isolates were observed in both Gram-positive and Gram-negative isolates. This finding is inconsistent with the previous studies conducted in Ethiopia. ${ }^{10,18}$ The reason for multidrug resistance in Ethiopia might be the unregulated over-the-counter sale of antimicrobials, mainly for self-treatment of suspected infection in humans without prescription, which would inevitably lead to the emergence and rapid dissemination of resistant strains. In addition, the availability of cheaper generic drugs (like amoxicillin) of variable quality in the market for treatment of bacterial infections may also contribute to the increased level of resistance. A study on the practice of self-medication in Jimma town showed that out of the 152 ill people, $27.6 \%$ were self-medicated. ${ }^{21}$ Generally, it is well known that microbial drug resistance is growing.

\section{Conclusion}

Overall prevalence of bacteremia in our study was $19.7 \%$. The Gram-positive isolates were predominant compared to the Gram-negative ones. Among all isolates, CoNS were predominant. Ciprofloxacin, vancomycin, ceftriaxone, and norfloxacin were the most effective drugs when compared to other drugs tested against both Gram-negative and Grampositive isolates. Our study results showed the presence of high rates of resistance to the most commonly used antibiotics used to treat bacterial infections. Multiple drug resistance was observed in 94 (84\%) of the Gram-positive and 57 (92\%) of the Gram-negative isolates.

\section{Recommendations}

Empirical antibiotic treatment for Gram-negative and Grampositive bacteria must be taken into consideration because, 
nowadays, most of the isolated bacteria show high rates of resistance to the most commonly used drugs like ampicillin, amoxicillin, and tetracycline, etc. Therefore, treatment of bacteremia should be based on culture and sensitivity rather than on universal guidelines.

Routine bacterial surveillance and the study of their resistance pattern must be essential components in providing alternative drugs for resistant bacteria.

\section{Acknowledgments}

We would like to give our deepest gratitude and heartfelt thanks to the School of Biomedical and Laboratory Sciences, College of Medicine and Health, University of Gondar for their valuable comments and suggestions. We are also grateful to the digital library, computer center, and library staff for their overall support and cooperation. Finally, we would like to express our heartfelt gratitude to all our friends who gave comments and corrections.

\section{Disclosure}

The authors report no conflicts of interest in this work.

\section{References}

1. Forbes BA, Sahm DF, Weissfeld AS (editors). Bloodstream infection. In: Bailey \& Scott's Diagnostic Microbiology. Ch. 52. 12th ed. St Louis: Mosby Elsevier; 2007:778-794.

2. Kuppermann N. Occult bacteremia in young febrile children. Pediatr Clin North Am. 1999;46(6):1073-1109.

3. Bryan C. Clinical implications of positive blood cultures. Clin Microbiol Rev. 1989;2(4):329-353.

4. Panceri M, Vegni F, Goglio A, et al. An etiology and prognosis of bacteremia in Italy. Epidemiol Infect. 2004;132(4):647-654.

5. Javaloyas M, Garcia-Somoza D, Gudiol F. Epidemiology and prognosis of bacteremia: a 10-y study in a community hospital. Scand J Infect Dis. 2002;34(6):436-441.

6. Pedersen G, Schønheyder H, Sørensen H. Source of infection and other factors associated with case fatality in community-acquired bacteremia - a Danish population-based cohort study from 1992 to 1997. Clin Microbiol Infect. 2003;9(8):793-802.

7. Bennett I, Beeson P. Bacteremia: a consideration of some clinical and experimental aspects. Yale J Biol Med 1954;26(4):241-262.

8. Ali H, Ali M, Moammar N, Zeana S, Ruqia M, Nebras M. Etiologic agents of bacteremia among newborns in Hilla City. Med J Babylon. 2008;5(4):385-394.
9. Karunatharan R, Raja NS, Ng KP, Navaratnam P. Etiology of blood culture isolates among patients in a multidisciplinary teaching hospital in Kuala Lumpur. J Microbiol Immunol Infect. 2007;40(5):432-437.

10. Zenebe T, Kannan S, Yilma D, Beyene G. Invasive bacterial pathogens and their antibiotic susceptibility patterns in Jimma University Specialized Hospital, Jimma, Southwest Ethiopia. Ethiop J Health Sci. 2011;21(1):1-8.

11. Barber M. Methicillin-resistant staphylococci. J Clin Pathol 1961;14: 385-393.

12. Clinical and Laboratory Standards Institute. Performance Standards for Antimicrobial Susceptibility Testing: 15th Informational Supplement. Pennsylvania: CLSI; 2005. Supplemental tables. CLSI Publication M100-S15, M2-A8, and M7-A6.

13. Cheesbrough M. Biochemical tests to identify bacteria. In: District Laboratory Practice in Tropical Countries, Part 2, Ch. 7.5. Cambridge, UK: Cambridge University Press; 2000:62-70.

14. Asrat D, Amanuel Y. Prevalence and antibiotic susceptibility pattern of bacterial isolates from blood culture in Tikur Anbessa Hospital, Addis Ababa, Ethiopia. Ethiop Med J. 2001;39(2):97-104.

15. Garg A, Anupurba S, Garg J, Goyal RK, Sen MR. Bacteriological profile and antimicrobial resistance of blood culture isolates from a university hospital. JIACM. 2007;8(2):139-143.

16. Bhat YR, Lewis LE, Vandana KE. Bacterial isolates of early-onset neonatal sepsis and their antibiotic susceptibility pattern between 1998 and 2004: an audit from a center in India. Ital J Pediatr. 2011;37:32.

17. Bachou H, Tylleskär T, Kaddu-Mulindwa DH, Tumwine JK. Bacteraemia among severely malnourished children infected and uninfected with the human immunodeficiency virus-1 in Kampala, Uganda. BMC Infect Dis. 2006;6:160.

18. Ali J, Kebede Y. The frequency of isolation and antimicrobial susceptibility pattern of bacterial isolates from blood culture, University of Gondar teaching hospital, Northwest Ethiopia. Ethiop Med J. 2008;46(2):155-161.

19. Pourakbari B, Sadr A, Ashtiani MT, et al. Five-year evaluation of the antimicrobial susceptibility patterns of bacteria causing bloodstream infections in Iran. J Infect Dev Ctries. 2012;6(2):120-125.

20. Mehdinejad M, Khosravi AD, Morvaridi A. Study of prevalence and antimicrobial susceptibility pattern of bacteria isolated from blood cultures. J Biol Sci. 2009;9:249-253.

21. Worku S, G/Mariam A. Practice of self-medication in Jimma town. Ethiop J Health Dev. 2003;17(2):111-116.

22. Kalantar E, Motlagh M, Lordnejad H, Beiranvand S. The prevalence of bacteria isolated from blood cultures of Iranian children and study of their antimicrobial susceptibilities. Jundishapur J Nat Pharm Prod. 2008;3(1):1-7.

23. Karlowsky JA, Jones ME, Draghi DC, Thornsberry C, Sahm DM, Volturo GA. Prevalence and antimicrobial susceptibilities of bacteria isolated from blood cultures of hospitalized patients in the United States in 2002. Ann Clin Microbiol Antimicrob. 2004;3:7.

24. Horieh S, Marzieh L, Aliakbar K. Frequency of bacteria isolated from children's blood culture in a university hospital in Iran and their antibiotic susceptibility pattern. 30th Annual Meeting of the European Society for Paediatric Infectious Diseases; May 2012; Thessaloniki, Greece.
Pathology and Laboratory Medicine International

Publish your work in this journal

Pathology and Laboratory Medicine International is a peer-reviewed, open access journal focusing on innovative basic research and translational research related to pathology or human disease. The journal includes original research, updates, case reports, reviews and commentaries on current controversies. The manuscript management system is completely

\section{Dovepress}

online and includes a very quick and fair peer-review system. Visit http://www.dovepress.com/testimonials.php to read real quotes from published authors. 